\title{
Relationship of thyroid gland elasticity with age, gender and thyroid gland volume in the shear-wave ultrasound elastogra- phy
}

\author{
Furkan Ertürk Urfalı ${ }^{1} \oplus$, Sertaç Erarslan ${ }^{2} \odot$, Bahattin Özkul $^{3} \odot$, Mehmet Korkmaz $^{1} \oplus$, Sermin Tok \\ $\operatorname{Umay}^{1} \odot$
}

1Department of Radiology, Kütahya Health Sciences University, Faculty of Medicine, Kütahya, Turkey

2Department of Internal Medicine, Kütahya Health Sciences University, Faculty of Medicine, Kütahya, Turkey

3Department of Radiology, Istanbul Atlas University, Vocational School, İstanbul, Turkey

\begin{abstract}
Objectives: The aim of the study is to determine the correlation between thyroid gland elasticity with thyroxine, thyroid-stimulating hormone levels, age, gender and thyroid gland volume in the normal population.

Methods: The study was conducted with 105 healthy cases. Thyroid gland elasticity was evaluated in axial plan using ultrasonography.

Results: The relationship between thyroid gland elasticity and thyroxine, thyroid-stimulating hormone levels, age, gender and thyroid gland volume was evaluated. The mean thyroid gland volume was $11.95 \pm 9.23 \mathrm{~mm}$. A moderate negative correlation was found between thyroid gland volume and $\mathrm{kPa}$ value observed from the elastography examination. A moderate negative correlation was found between elastography $\mathrm{kPa}$ value and blood thyroxine level. No correlations were found between thyroid-stimulating hormone level, age, gender and thyroid gland elasticity.

Conclusions: The negative correlation between thyroid gland volume and thyroxine level with thyroid gland elasticity should be considered in elastographic evaluations.

Keywords: Ultrasonography, elastography, thyroid, volume
\end{abstract}

Nhear-wave ultrasound elastography (SWE) is a quantitative method used to measure the stiffness of tissues [1]. SWE applies vibration on tissues with a focused ultrasound pulse produced by the ultrasound transducer. The rate of vibration spreading within the tissue increases in parallel with the increase in the stiffness of the tissues [2]. SWE is often used to evaluate diffuse thyroid diseases and thyroid nodules [3]. The risk of malignancy increases as the stiffness in the thyroid nodules increases [3-5]. Thyroid gland elasticity also increases in thyroid gland inflammation [1].
The aim of the study is to determine the correlation between the thyroid gland elasticity in cases with normal thyroid function tests and no thyroid pathology, with thyroxine (T4), thyroid-stimulating hormone (TSH) levels, age, gender and thyroid volume with SWE.

\section{METHODS}

The study included 105 healthy individuals. Inclu-

How to cite this article: Urfall FE, Erarslan $S$, Özkul B, Korkmaz M, Tok Umay S. Relationship of thyroid gland elasticity with age, gender and thyroid gland volume in the shear-wave ultrasound elastography. Eur Res J 2022;8(1):118-121. DOI: 10.18621/eurj. 1003763 
sion criteria were healthy individuals who had normal thyroid functions tests within the last two weeks. Exclusion criteria were as follows: 1) TSH or T4 levels anomaly; 2) Thyroiditis history; 3) Use of drugs affecting thyroid hormones; 4) History of thyroid operation; 5) Nodule in thyroid gland; 6) Radiotherapy of neck for any reason; 7) History of radioactive iodine use; 8) Thyroid hemiagenesis or ectopic thyroid tissue. This prospective study was approved by the institutional review board of the Ethical Committee of our hospital. Written informed consent was obtained from all parents.

\section{SWE Measurement}

Two radiologists examined all the patients by SWE. They were blinded to each other's examinations. The US elastography evaluations were performed using a US system (Acuson S3000; Siemens Medical Solutions, Mountain View, CA) with a linear transducer that enabled scanning with a frequency ranging from 4 to $9 \mathrm{MHz}$.

Thyroid gland was evaluated in supine position with B-mod US. Thyroid gland volume was calculated. Then, thyroid gland elasticity was evaluated in supine position. The Tissue elasticity was measured by Virtual Touch tissue quantification software quantitatively (Siemens Medical Solutions). The examination was repeated until high-quality data were collected with color coded quality maps. The highquality data were frozen and saved. The region of in- terest (ROI) of the system was set to include the muscle. A rectangular electronic box-shaped region of interest of $5 \times 5 \mathrm{~mm}$ was used for SWE measurements. Additionally, an SWE scale of $0-10 \mathrm{~m} / \mathrm{s}$ was chosen. All measurements were repeated for 10 times in the largest area of the thyroid gland in the axial plan (Fig. 1). The mean of 10 measurements was automatically determined.

\section{Statistical Analysis}

The statistical analysis was conducted with SPSS software (version 21.0; IBM Corporation, Armonk, NY). The descriptive statistics in the study were given as mean and standard deviation. All data showed normal distribution with the Kolmogorov-Smirnov test. The correlation between thyroid gland and $\mathrm{kPa}-\mathrm{Vms}$ values observed in the elastographic examination and gland volume, blood T4-TSH values and cases were analyzed with Pearson correlation coefficient test analysis. The correlation coefficients were regarded as perfect when $r \geq 0.91$, as good when $0.90 \geq r \geq 0.71$, as moderate when $0.70 \geq r \geq 0.51$, as weak when 0.50 $\geq \mathrm{r} \geq 0.31$ and nonexistence when $\mathrm{r} \leq 0.3$. The statistical significance level was $p<.05$.

\section{RESULTS}

The ages of the persons changed between 22 and 61 years (mean; $44.71 \pm 10.23$ years). Of these per-

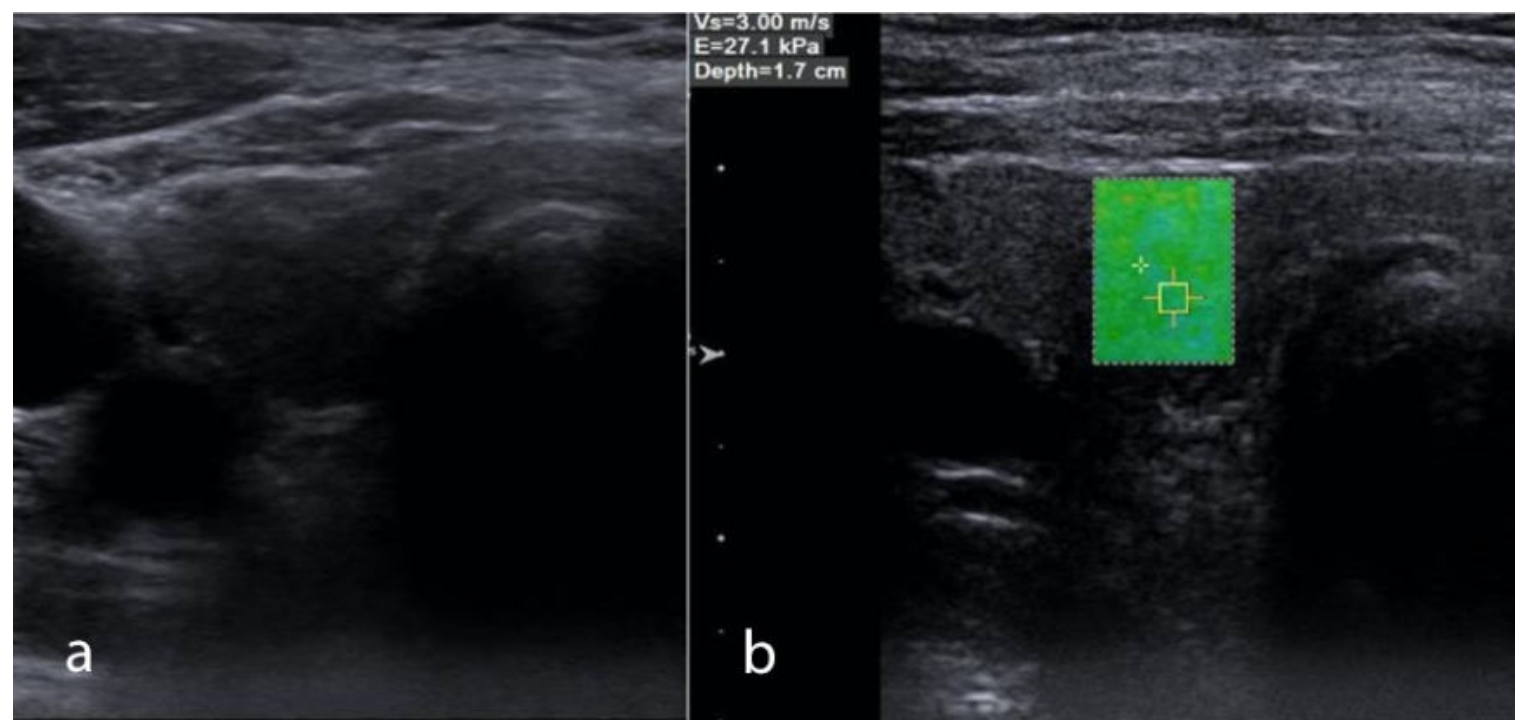

Fig. 1. (A) On B mod ultrasonography, the largest area in the thyroid right lob in axial plan, (B) Measurement made with SWE in the largest region in the axial plan. 
Table 1. Descriptive analysis of the cases included in the study

\begin{tabular}{lcc}
\hline & Mean \pm Standard Deviation & Min.-Max. \\
\hline Age (years) & $44.71 \pm 10.23$ & $22-61$ \\
$\begin{array}{l}\text { Thyroid gland total volume } \\
\left(\mathbf{m m}^{\mathbf{3}}\right)\end{array}$ & $11.95 \pm 9.23$ & $5-44.75$ \\
$\begin{array}{l}\text { Thyroid gland elasticity } \\
(\mathbf{k P a})\end{array}$ & $13.01 \pm 5.21$ & $3.7-21.5$ \\
T4 level (ng/dL) & & \\
TSH $(\mathbf{m U} / \mathbf{m L})$ & $0.87 \pm 0.17$ & $0.61-1.15$ \\
\hline
\end{tabular}

$\mathrm{T} 4=$ thyroxine, $\mathrm{TSH}=$ thyroid-stimulating hormone

sons, 52 were males (mean age, 42.8 years; age range, 20-55 years), and 53 were females (mean age, 46.1 years; age range, 22-61 years).The mean thyroid gland volume was $11.95 \pm 9.23 \mathrm{~mm} 3$. The descriptive data in the study were shown in Table 1.

A moderate negative correlation was found between thyroid gland volume and $\mathrm{kPa}$ value that was observed from the elastographic examination. A moderate negative correlation was found between elastography $\mathrm{kPa}$ value and blood $\mathrm{T} 4$ level while a weak positive correlation was found between elastography and blood TSH level. A weak negative correlation was found between age and $\mathrm{kPa}$ value. No correlations were found between gender and $\mathrm{kPa}$ value (Table 2).

\section{DISCUSSION}

Thyroid gland pathologies in adult patients and SWE examination results were evaluated in various studies [5-8]. The SWE value of the normal thyroid gland was evaluated in the limited number of studies [9-11].

The aim of the study was to determine the correlation between the thyroid gland elasticity with TSH, T4 levels, age, gender and thyroid gland volume in normal population, with SWE.

Arda et al. [7] was found $10.97 \pm 3.1 \mathrm{kPa}$ (range, $1-24 \mathrm{kPa}$ ) of the mean thyroid gland elasticity in the normal population [9]. The thyroid gland elasticity was found to be higher among women in this study. No correlations were found with age [9]. The mean thyroid gland elasticity value was $13.01 \pm 5.21$ in the present study. Unlike the study by Arda et al. [7], no significant differences were found with respect to gender in terms of thyroid gland elasticity. The correlation with thyroid volume and T4 was also evaluated in the present study unlike the study by Arda et al. [7]. A moderate negative correlation was found between elasticity and thyroid volume and T4 value in the study.

In a study conducted by Herman et al. [11] the elasticity of the neck anatomical structures in the normal population was evaluated and the mean thyroid gland elasticity was found as $9.5 \pm 3.6 \mathrm{kPa}$. However, incidental thyroid nodules were detected in their study [11]. The cases with incidental nodules were excluded from our study.

It was found that thyroid gland elasticity is correlated with age, weight and height in the study by Habibi et al. conducted with normal children [10].Similarly, Uysal et al. [12], who conducted a study with children found a correlation with age. No correlations were found with age among adult cases in our study.

Sedlackova et al. [8], who conducted a study on diffuse thyroid diseases found a correlation between thyroid volume and stiffness similar to the present

Table 2. Pearson correlation test analysis between the elastography parameter of the cases and thyroid gland volume, blood T4-TSH levels, age, gender

\begin{tabular}{|c|c|c|c|c|c|c|c|c|c|c|}
\hline \multicolumn{3}{|c|}{$\begin{array}{c}\text { Thyroid Gland } \\
\text { Volume }\end{array}$} & \multicolumn{2}{|c|}{ TSH } & \multicolumn{2}{|c|}{ T4 } & \multicolumn{2}{|c|}{ Age } & \multicolumn{2}{|c|}{ Gender } \\
\hline $\mathrm{kPa}$ & $\mathrm{k}:-0.680^{* *}$ & $p<0.001$ & k: $0.468^{*}$ & $p<0.001$ & $\mathrm{k}: 0.636^{* *}$ & $p<0.001$ & k:-0.499* & $p<0.001$ & k: 0.107 & $p=0.276$ \\
\hline
\end{tabular}


study. No evaluation was performed in terms of age, gender, T4 and TSH levels in the study by Sedlackova et al. [8]. Previously, correlations were found between inflammation level and sclerosis with stiffness in diffuse thyroid diseases in [5].

\section{Limitations}

The main limitation in this study is that thyroid gland pathological evaluation was not conducted. Another limitation is the number of cases.

\section{CONCLUSION}

In conclusion, we used SWE to determine the elasticity values of various normal thyroid gland. Thyroid gland elasticity was not affected by age, gender, and TSH level. A moderate negative correlation was found between thyroid gland volume and T4 level with thyroid gland elasticity. Normal thyroid gland elasticity value can be used as a base value in the future studies. Additionally, the negative correlation between thyroid gland volume and T4 level with elasticity should be considered in elastographic evaluations.

\section{Authors' Contribution}

Study Conception: FEU, STU, SE; Study Design: FEU, BÖ, MK; Supervision: MK, STU; Funding: FEU, BÖ, SE; Materials: SE, BÖ, STU; Data Collection and/or Processing: FEU, SE, MK; Statistical Analysis and/or Data Interpretation: FEU, SE, STU; Literature Review: FEU, BÖ, MK; Manuscript Preparation: FEU, STU and Critical Review: MK, STU, BÖ.

\section{Conflict of interest}

The authors disclosed no conflict of interest during the preparation or publication of this manuscript.

\section{Financing}

The authors disclosed that they did not receive any grant during conduction or writing of this study.

\section{REFERENCES}

1. Bakırtaş Palabıyık F, İnci E, Papatya Çakır ED, Hocaoğlu E. Evaluation of normal thyroid tissue and autoimmune thyroiditis in children using shear wave elastography. J Clin Res Pediatr Endocrinol 2019;11:132-9.

2. Taljanovic MS, Gimber LH, Becker GW, Latt LD, Klauser AS, Melville DM, et al. Shear-wave elastography: basic physics and musculoskeletal applications. Radiographics 2017;37:855-70.

3. Cantisani V, Lodise P, Grazhdani H, Mancuso E, Maggini E, Di Rocco G, et al. Ultrasound elastography in the evaluation of thyroid pathology. Current status. Eur J Radiol 2014;83:420-8.

4. Zhao CK, Chen SG, Alizad A, He YP, Wang Q, Wang D, et al. Three-dimensional shear wave elastography for differentiating benign from malignant thyroid nodules. J Ultrasound Med 2018;37:1777-88.

5. Dudea SM, Botar-Jid C. Ultrasound elastography in thyroid disease. Med Ultrason 2015;17:74-96.

6. Fukuhara T, Matsuda E, Endo Y, Takenobu M, Izawa S, Fujiwara $\mathrm{K}$, et al. Correlation between quantitative shear wave elastography and pathologic structures of thyroid lesions. Ultrasound Med Biol. 2015;41:2326-32.

7. Vlad M, Golu I, Bota S, Vlad A, Timar B, Timar R, et al. Realtime shear wave elastography may predict autoimmune thyroid disease. Wien Klin Wochenschr 2015;127:330-36.

8. Sedlackova Z, Herman J, Furst T, Salzman R, Vachutka J, Herman M. Shear wave elastography in diffuse thyroid disease. Biomed Pap Med Fac Univ Palacky Olomouc Czech Repub 2021;165:152-6.

9. Arda K, Ciledag N, Aktas E, Aribas BK, Köse K. Quantitative assessment of normal soft-tissue elasticity using shear-wave ultrasound elastography. AJR Am J Roentgenol 2011;197:532-6.

10. Habibi HA, Memis Durmaz ES, Qarayeva V, Kandemirli SG, Kalyonucu Ucar A, Aslan M, et al. Quantitative assessment of thyroid, submandibular, and parotid glands elasticity with shearwave elastography in children. Ultrasound Q 2018;34:58-61.

11. Herman J, Sedlackova Z, Vachutka J, Furst T, Salzman R, Vomacka J. Shear wave elastography parameters of normal soft tissues of the neck. Biomed Pap Med Fac Univ Palacky Olomouc Czech Repub 2017;161:320-5.

12. Uysal E, Öztürk M. Quantitative Assessment of thyroid glands in healthy children with shear wave elastography. Ultrasound Q 2019;35:297-300. 